\title{
OTRAS FALACIAS
}

uan Ramón Capella introduce la cuestión de la «ética de la responsabilidad»a través de un supuesto en el que se presentan aparentemente unidos por una relación causal tres sucesos: Tortura, Confesión y Evitación del mal. A continuación, presenta una colección de hipótesis posibles que vienen a poner de manifiesto que tal relación causal es, en efecto, ilusoria, porque la posibilidad de que la aparición consecutiva de esos sucesos se rija por ella es remotísima. La presunta fuerza causal de la tortura resulta así ser puramente «mágica», inventada. En realidad el supuesto acaba por ser, en la versión que resulta del análisis de Capella, una secuencia de sucesos aleatorios (El factor azar aparece en la forma de «héroe anónimo»). Como tales sucesos aleatorios, ninguno de ellos tiene vinculación alguna con el antecedente o el consecuente. Hasta tal punto que cabría incluso pensar en posibilidades en las que no se diera ni la secuencia temporal: por ejemplo, el héroe anónimo evita el mal segundos antes de que empiece la tortura. Naturalmente, reformulado así el supuesto, la acción de torturar carece en absoluto de justificación porque el único cambio que introduce en el mundo es la tortura misma, es decir, un mal puro y simple sin consecuencias ulteriores. Y Capella lo rechaza con toda razón, como lo haría cualquiera. Pero temo que ello no refuta los argumentos en que se basa la llamada «ética de la responsabilidad» porque esta ética pretende entrar en juego sólo cuando se da la existencia de dichas relaciones causales.

Hagamos de abogado del «diablo» (al fin y al cabo Weber mantenía que los éticos de resultados pactaban con el diablo). Un defensor de la ética de responsabilidad recurriría a un ardid contrario al argumento de Capella: en lugar de negar o minimizar la relación causal entre los sucesos tendería a magnificarla hasta convertir el supuesto en una secuencia de sucesos seguros implicados causalmente. Afirmaría: «Sólo si se tortura al detenido éste confiesa, y sólo si confiesa se evita el mal.» Si esto resultara 
ser una secuencia de hechos seguros, no aleatorios, entonces la conclusión «Sólo si se tortura al detenido se evita el mal» sería una proposición verdadera. Estaríamos en presencia de un dilema trágico, de los que gustan alegar los éticos de la responsabilidad. Que esto no sea así en el caso de la tortura no quiere decir que no sea así en ningún caso, que es lo que parece sugerir Capella.

Para situar la cuestión en un marco de análisis satisfactorio hay que tener en cuenta, en primer lugar, que, en efecto, nuestras acciones introducen cambios en el mundo y, por tanto, tienen consecuencias que se producen en el mundo. Y, en segundo lugar, que, sin embargo, el grado de previsibilidad de esas consecuencias puede ser muy variable porque no siempre (aunque tampoco nunca) nuestras acciones son la única génesis causal que produce tales consecuencias, sino una entre muchas causas, previsibles unas e imprevisibles otras. Para expresar lo primero en términos éticos podría partirse de un cuadro sencillo de cuatro posibilidades:
A) Acción según principios que es causa de buenas consecuencias.
B) Acción según principios que es causa de malas consecuencias.
C) Acción contra principios que es causa de buenas consecuencias.
D) Acción contra principios que es causa de malas consecuencias.

Capella excluye expresamente la posibilidad B sugiriendo que los principios éticos siempre producen buenas consecuencias. De lo contrario no serían «buenos» principios. Esto me parece que es introducir la conclusión en las premisas que usa, lo que es la definición canónica de petición de principio. Más extraño es que no mencione siquiera la posibilidad $\mathrm{C}$, que es, sin embargo, el núcleo del razonamiento de la ética de la responsabilidad, y la que la ha acreditado, incluso en la literatura, como una posibilidad real: «las manos sucias.» $\mathrm{Si}$ esta omisión se debe a que piensa, en conexión lógica con lo anterior, que cuando no se actúa según principios no se causan buenas consecuencias, entonces está cometiendo otra falacia: negar el antecedente.

Incluyamos, por último, en el cuadro el problema del grado de previsibilidad de las consecuencias, o lo que es lo mismo, de fuerza causal de la acción según principios o contra principios. Capella critica, con razón, a quienes dan por seguro un suceso 
(«La situación hipotética») que, ni es tan seguro ni, en el mejor de los casos, depende directamente de su acción, sino de la de «otros agentes», pero con esto lo único que demuestra es que cuando el suceso hipotético en cuestión es de verificación remota alegarlo como posible como justificación para no actuar según principios es tan fantasmagórico como el flogisto. En esas condiciones la ética de la responsabilidad no es mas que un simulacro de razonamiento moral. Pero ello no quiere decir que esas condiciones se den siempre. Hay circunstancias en que se pueden anticipar con claridad «situaciones hipotéticas» que producen probablemente un mal, y actuar para evitarlas constituye una exigencia moral, y una exigencia moral que puede entrar en contradicción con nuestros principios. Capella sugiere que si nuestros principios son «buenos» nos impondrán actuar de forma que eviternos el mal, pero si actuamos así cancelaremos la posibilidad de que la «situación hipotética» se produzca. Es decir, recurriremos a una situación que «no puede producirse sola» y la excluiremos «con nuestra conducta de principios». El flogisto, que había fracasado en su malévola intención de defender ta ética de la responsabilidad, triunfa ahora en la justificación de los principios. Como debe ser. 